Las estructuras clínicas a partir de Lacan. Vol. I - Intervalo y holófrase, locura, psicosis, psicossomática y debilidade Vol. II - Neurosis, histeria, obsesión, fobia, fetichismo y perversiones Alfredo Eidelsztein Buenos Aires: Letra Viva, 2008, 341 págs. (Vol. I) e 254 págs. (Vol. II)

\title{
Um sistema para as estruturas clínicas
}

\author{
Marta Regina de Leão D’Agord*1 \\ Vitor Hugo Couto Triska*2
}

182

\begin{abstract}
Alfredo Eidelsztein - autor de Modelos, esquemas y grafos en la enseñanza de Lacan, El grafo del deseo e La topologia em la clínica psicoanalítica, elabora os fundamentos da noção de estrutura clínica. No método pelo qual identifica a particularidade de cada estrutura está o mérito do psicanalista argentino. Propondo uma estrutura das estruturas clínicas - sendo estrutura, de acordo com a definição do próprio Lacan, "um conjunto covariante de significantes" onde a identidade dos termos é obtida por suas diferenças —, é dentro de um sistema de relações de oposição e vizinhança que cada estrutura clínica será apresentada. Ao mesmo tempo em que busca ser fiel aos textos lacanianos (as citações e matemas abundantes e cuidadosamente analisados o atestam), a maneira como os interpreta não é óbvia, mesmo para o leitor já familiarizado com Lacan. O manejo das formalizações, frequentemente evitadas por seus comentadores, é didático e conduz a conclusões clínico-teóricas cruciais, o que demonstra
\end{abstract}

*1,2 Universidade Federal do Rio Grande do Sul - UFRS (Porto Alegre, RS, Br). 


\section{RESENHAS BIBLIOGRÁFICAS}

que Eidelsztein as toma como os próprios conceitos, não apenas suas figuras. Exemplo disso é a análise crítica dos esquemas R e I, onde I é uma distorção de $\mathrm{R}$ determinada pela falta da extração do objeto $a$. Essa distorção serve de fundamento epistemológico à oposição organizadora e principal da estrutura das estruturas, a saber, entre holófrase e intervalo, os dois grandes grupos que reúnem as estruturas clínicas trabalhadas pelo autor.

A obra está dividida em dois volumes. O primeiro possui 11 capítulos, dos quais os dois primeiros são dedicados a questões teóricas preliminares, como o sujeito da ciência, a clínica "mais além do pai" e o quadro das estruturas clínicas. Eidelsztein apresenta a psicanálise como a resposta criada por Freud ao mal-estar ineludível a todo sujeito falante na cultura ocidental — definida segundo três fundamentos: linguístico (indo-europeu), religioso (tradição judaico-cristã) e de elaboração do saber (ciência moderna). É apenas circunscrita a esse contexto cultural que a teoria psicanalítica das estruturas clínicas poderia ser aplicada, ficando incerta a sua pertinência em outros contextos. A extração do objeto $a$ (nome da falta no Outro) serve como operador teórico chave. Além da oposição holófrase-intervalo, também sustenta a distinção entre uma clínica "do pai" e outra "mais além do pai". Na primeira clínica, o Nome-do-Pai é um elemento instaurador da falta no Outro. Essa leitura é criticada pelo autor porque faria do pai um limite máximo, um Outro do Outro que impõe sua lei — uma "fantasia neurótica". Na clínica "mais além do pai", a prevalência é dada à incompletude fundamental da estrutura significante, que pode ou não ser "legalizada", isto é, organizar-se segundo o Nome-do-Pai. O "mais além do pai", ou seja, a falta estrutural no Outro, organizará toda a estrutura das estruturas clínicas, pois é a partir de suas diferentes relações com essa falta que elas serão estabelecidas. O volume I ainda trata de um tema pouco discutido na literatura lacaniana, a saber, a loucura como distinta da psicose, além das estruturas de holófrase: psicose, psicossomática e debilidade mental.

No quadro apresentado no capítulo 2 do volume I aparecem outros tipos clínicos (adições, hipocondria, melancolia etc.) não articulados com o quadro das estruturas, seja porque não o são, seja porque a teoria psicanalítica ainda não pôde apreendê-las e colocá-las em relação às demais estruturas. Serviriam como demonstração da insuficiência da teoria ou, talvez, da impossibilidade radical de formalização: nem toda psicopatologia será compreendida pelo critério de extração do objeto $a$.

O segundo volume trata das estruturas de extração do objeto $a$, ou seja, de intervalo (neuroses, histeria, obsessão, fobia, fetichismo e perversões) e está dividido em dez capítulos e um post-scriptum. Não é apenas uma continuação do primeiro volume, pois traz questões que ainda não haviam sido discutidas no volume I, como o termo "estruturas clínicas". A fórmula do fantasma é o matema 
central desse volume. A inversão dessa fórmula, explorada minuciosamente pelo autor, sustentará a oposição entre o par neuroses-perversões. Histeria e obsessão também serão comparadas e diferenciadas a partir desse matema. Interessante notar que a fobia é, não por acaso, colocada mais próxima das perversões do que as demais neuroses: já que o quadro das estruturas é proposto como o esquema da estrutura das estruturas, a posição dos elementos no quadro representa as relações da própria estrutura. Por isso, e assim como as demais estruturas, a fobia será definida em articulação com a perversão que lhe é mais próxima, a saber, o fetichismo.

\begin{tabular}{|c|c|c|c|c|c|c|c|c|c|}
\hline \multirow[b]{3}{*}{ 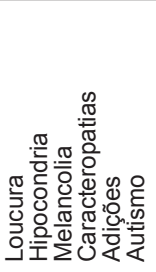 } & \multicolumn{5}{|c|}{ Intervalo (extração do objeto a) } & \multirow[b]{3}{*}{ 密 } & \multicolumn{3}{|c|}{ Holófrase (Não extração do objeto a) } \\
\hline & \multicolumn{3}{|c|}{ Neurose } & \multirow[b]{2}{*}{ 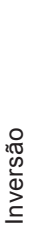 } & \multirow[b]{2}{*}{ Perversão } & & \multirow[b]{2}{*}{ Psicose } & \multirow[b]{2}{*}{$\begin{array}{l}\text { Debilidade } \\
\text { Mental }\end{array}$} & \multirow[b]{2}{*}{$\begin{array}{l}\text { Resposta } \\
\text { Psicossomá- } \\
\text { tica }\end{array}$} \\
\hline & Obsessão & Histeria & Fobia & & & & & & \\
\hline
\end{tabular}

(p. 76, vol. I)

O post-scriptum, finalmente, sistematiza as diferenças espaciais entre o sujeito tomado no sentido filosófico e científico na obra de Freud, e o sujeito como conceito da teoria psicanalítica em Lacan. As rupturas entre Freud e Lacan, presentes em ambos os volumes apenas de maneira secundária, são aqui expostas em primeiro plano e esclarecem a leitura de Eidelsztein, segundo a qual as formalizações servem de fundamento epistemológico dos conceitos.

Uma leitura crítica desses dois volumes aponta para a seguinte questão: se o sistema da estrutura supõe uma falta, isto é, a operatividade do significante, da diferença, como pensar uma estrutura que não seja intervalar? As questões que os dois volumes suscitam são importantes para os pesquisadores que buscam fundamentos epistemológicos da psicopatologia e da psicanálise, assim como para o clínico interessado em fundamentar sua prática.

Citação/Citation: D’Agord, M.R. de L., Triska, V.H.C. (2016, março). Um sistema para as estruturas clínicas. Resenha do livro Las estructuras clínicas a partir de Lacan. Vol. I: Intervalo y holófrase, locura, psicosis, psicossomática y debilidade mental. Vol II: Neurosis, 


\section{RESENHAS BIBLIOGRÁFICAS}

histeria, obsesión, fobia, fetichis,mo y perversiones. Revista Latinoamericana de Psicopatologia Fundamental, 19(1), 182-185.

Editor do artigo/Editor: Profa. Dra. Sonia Leite

Recebido/Received: 26.3.2015/ 3.26.2015 Aceito/Accepted: 30.3.2015 / 3.30.2015

Copyright: (C) 2009 Associação Universitária de Pesquisa em Psicopatologia Fundamental/ University Association for Research in Fundamental Psychopathology. Este é um artigo de livre acesso, que permite uso irrestrito, distribuição e reprodução em qualquer meio, desde que o autor e a fonte sejam citados / This is an open-access article, which permits unrestricted use, distribution, and reproduction in any medium, provided the original authors and sources are credited.

\section{Marta Regina de Leão D’Agord}

Professora do Departamento de Psicanálise e Psicopatologia do Instituto de Psicologia da Universidade Federal do Rio Grande do Sul - UFRGS (Porto Alegre, RS, BR) e dos PPGs, Psicanálise: Clínica e Cultura; Psicologia Social e Institucional.

Rua Riveira, 600

90670-160 Porto Alegre, RS, Br

e-mail: mdagord@terra.com.br

\section{Vitor Hugo Couto Triska}

Psicanalista; Doutorando no PPG Psicologia Social e Institucional da Universidade Federal do Rio Grande do Sul - UFRGS (Porto Alegre, RS, BR) .

Rua Dario Pederneiras, 3454/403

90630-090 Porto Alegre, RS, Br

e-mail: vhtriska@gmail.com

This is an open-access article, which permits unrestricted use, distribution, 